\title{
CARACTERIZAÇÃO DE TRÊS GENÓTIPOS DE UMEZEIRO (Prunus mume Sieb. et Zucc.) POR MARCADORES RAPD ${ }^{1}$
}

\author{
NEWTONALEX MAYER ${ }^{2}$, ELIANA GERTRUDES DE MACEDO LEMOS ${ }^{3}$, FERNANDO MENDES PEREIRA $^{4}$, ESTER WICKERT
}

RESUMO - Um projeto de pesquisa visando à utilização de clones de umezeiro (Prunus mume Sieb. et Zucc.) como porta-enxertos para pessegueiro [Prunus persica (L.) Batsch] está sendo conduzido na FCAV/UNESP, Câmpus de Jaboticabal-SP, com promissoras perspectivas de sucesso. Três genótipos de umezeiro foram selecionados de acordo com características agronômicas desejáveis para esta finalidade. A distinção dos três genótipos entre si, baseada exclusivamente em características morfológicas, apresenta limitações. Dessa forma, o objetivo do presente trabalho foi identificar marcadores RAPD capazes de diferenciar e caracterizar os Clones $05,15 \mathrm{e}$ a cv. Rigitano (Clone 10) de umezeiro, utilizando-se das cultivares Aurora-1 e Okinawa de pessegueiro como outgroup. Dos 220 primers testados, foram selecionados 42 , que amplificaram todos os cinco genótipos. Verificou-se que os marcadores RAPD permitiram a distinção entre o Clone 05, o Clone 15 e a cv. Rigitano de umezeiro, demonstrando a existência de variabilidade genética entre os mesmos. Dentre os três genótipos de umezeiro estudados, constatou-se que a similaridade genética é maior entre o Clone 05 e o Clone 15.

Temos para indexação: frutas de caroço, porta-enxerto, marcadores moleculares.

\section{CHARACTERIZATION OF THREE MUME GENOTYPES (Prunus mume Sieb. et Zucc.) BY RAPD MARKERS}

\begin{abstract}
A research project with the objective do develop mume clones (Prunus mume Sieb. et Zucc.), to be used as rootstocks for peach tree [Prunus persica (L.) Batsch] is been carried out at the Faculdade de Ciências Agrárias e Veterinárias (FCAV/UNESP), Jaboticabal Campus, São Paulo State, Brazil. These project showed promising perspectives of success, with three clones that were selected according to their characteristics for peach rootstock. But the distinction of the three clones among them, based only in morphologic characteristics, has presented limitations. The objective of the present research was to identify RAPD markers able to characterize and differentiate the 05 and 15 Clones and Rigitano mume cultivar, using Aurora-1 and Okinawa peach tree as outgroup. Among the 220 tested primers, 42 were selected and used to amplify the five genotypes. RAPD markers allowed the distinction among 05 Clone, 15 Clone and Rigitano, selected in FCAV/UNESP, showing presence of genetic diversity among them. These markers also showed that among the three mume genotypes studied, the genetic similarity is bigger between 05 Clone and 15 Clone.
\end{abstract}

Index terms: stone fruits, rootstock, molecular markers.

\section{INTRODUÇÃO}

O gênero Prunus inclui aproximadamente 200 espécies e é dividido em 6 subgêneros, que são: 1) Prunophora (ameixeiras em sua maioria); 2) Amygdalus (pessegueiros e amendoeiras); 3) Cerasus (cerejeiras); 4) Lithocerasus (cerejeiras); 5) Padus (cerejeiras de cachos), e 6) Laurocerasus (cerejeiras amarelas). O subgênero Prunophora é subdividido em 3 seções: a) Euprunus (ameixeiras européias e asiáticas); b) Prunocerasus (ameixeiras americanas), e c) Armeniaca (damasqueiro e umezeiro) (Rehder, 1940, citado por Shimada et al., 2001). Entretanto, devido à facilidade de hibridização natural entre as espécies do gênero Prunus, a classificação botânica tem sido controversa em alguns casos, em função da facilidade de desenvolvimento de tipos intermediários entre duas espécies (Dosba, 1994, citado por Casas et al., 1999).
No caso de ameixeiras, há ocorrência de cultivares autoincompatíveis e, em muitos casos, há dificuldade em determinar se uma cultivar provém de uma única espécie ou do cruzamento entre diferentes espécies. Outras cultivares são híbridas e resultam de cruzamentos naturais entre espécies de ameixeiras, umezeiro, damasqueiro ou até mesmo com pessegueiro, o que tem dificultado a identificação de cultivares segundo sua origem (Shimada et al., 1999).

A identificação de cultivares de frutíferas tem sido baseada em características morfológicas e agronômicas dos genótipos. Entretanto, existe substancial variação intraespecífica, especialmente nas características de folhas e de frutos, o que dificulta a distinção dos genótipos baseando-se somente na morfologia externa, além de ser um processo lento, devido ao longo período de juvenilidade das plantas lenhosas. Tratandose de porta-enxertos, a identificação de caracteres morfológicos é ainda mais difícil após a enxertia, além do que estes caracteres

${ }^{1}$ (Trabalho 197-07).Recebido em: 13-08-2007. Aceito para publicação em: 17-07-2008

${ }^{2}$ Embrapa Clima Temperado, BR 392, Km 78, CP 403, 96001-970, Pelotas-RS. E-mail: alex@cpact.embrapa.br.

${ }^{3}$ Universidade Estadual Paulista (UNESP), Faculdade de Ciências Agrárias e Veterinárias (FCAV), Depto. de Tecnologia, Via de Acesso Prof. Paulo Donato Castellane, s/n, CEP 14884-900, Jaboticabal-SP. E-mail: egerle@fcav.unesp.br, ewickert@ terra.com.br.

${ }^{4}$ UNESP/FCAV, Depto de Produção Vegetal, Via de Acesso Prof. Paulo Donato Castellane, s/n, CEP 14884-900, Jaboticabal-SP. E-mail: inagrojab@yahoo.com.br 
são geralmente influenciados por fatores ambientais e pelo estádio de crescimento da planta (Casas et al., 1999; Wünsch \& Hormaza, 2002).

Marcadores RAPD (Randomly Amplified Polymorphic DNA) têm sido utilizados em diferentes espécies de frutíferas, inclusive para o gênero Prunus. Shimada et al. (2001) estudaram a diversidade genética de 4 espécies de Prunus, subgênero Lithocerasus, utilizando 40 diferentes acessos, sendo que marcadores RAPD permitiram a diferenciação de todos os acessos. Em um estudo com 42 diferentes acessos de ameixeira (Prunus salicina), marcadores moleculares também foram eficientes na discriminação de todos os acessos (Shimada et al., 1999). Os autores concluíram que a técnica de RAPD é viável para identificar diferentes acessos de ameixeira.

A relação genética entre 54 cultivares de umezeiro foi estudada com estes mesmos marcadores, possibilitando a classificação em 7 diferentes grupos, concordando com sua origem geográfica (Shimada et al., 1994, citado por Wünsch \& Hormaza, 2002). Em damasqueiros (Prunus armeniaca), o uso de marcadores RAPD possibilitou a distinção de 19 cultivares originárias de 4 diferentes regiões geográficas (Mariniello et al., 2002).

Em um projeto de pesquisa visando à seleção de clones de umezeiro para utilização como porta-enxerto de pessegueiro, três clones, identificados como Clone 05, Clone 10 e Clone 15, foram considerados promissores. Os três clones foram selecionados na Faculdade de Ciências Agrárias e Veterinárias (FCAV/UNESP), em função de características desejáveis, destacando-se a resistência a Meloidogyne javanica (Mayer et al., 2003) e M. incognita (Mayer et al., 2005) e o menor vigor do Clone 10 (Mayer \& Pereira, 2006). O avanço dos estudos permitiu o lançamento da cultivar Rigitano (Pereira et al., 2007), inicialmente selecionada como Clone 10. Entretanto, essa cultivar apresenta características morfológicas muito semelhantes aos outros dois genótipos, os Clones 05 e 15, de tal forma que se mostraram limitantes para a discriminação dos três genótipos entre si, pela possibilidade de serem influenciados pelas condições ambientais. Dessa forma, estudos moleculares visando à distinção dos genótipos em nível molecular tornam-se necessários, uma vez que fornecem subsídios e informações para viabilizar o processo de registro dos genótipos, além do controle sobre a identidade genética dos porta-enxertos, que é essencial na certificação de mudas utilizadas na fruticultura moderna.

O objetivo do presente trabalho foi identificar marcadores moleculares RAPD capazes de diferenciar e caracterizar o Clone 05, o Clone 15 e a cv. Rigitano de umezeiro, selecionados na FCAV/UNESP, Câmpus de Jaboticabal-SP como porta-enxertos para pessegueiro.

\section{MATERIAL E MÉTODOS}

a) Obtenção dos clones. A partir de um lote de plantas de umezeiro (Prunus mume Sieb. et Zucc.), propagadas por germinação de sementes oriundas de genitores desconhecidos e mantidas em cultivo na Estação Experimental de Jundiaí - IAC, foram colhidos ramos herbáceos de cada planta, individualmente identificados. Esses ramos foram transportados ao Ripado de Fruticultura do Departamento de Produção Vegetal da FCAV/ UNESP, onde se iniciaram os trabalhos de seleção para características agronômicas desejáveis como porta-enxertos, em 1998 (Nachtigal et al., 1999; Pereira et al., 2007).

Os três genótipos que se destacaram - o Clone 05 , o Clone 10 (cv. Rigitano) e o Clone 15, foram propagados por enraizamento de estacas herbáceas (Mayer et al., 2001). Após aclimatação em viveiro, os clones foram transplantados para o campo, em maio de 2002, sob espaçamento de 0,5 m entre plantas, em área experimental localizada no Sítio São João, Município de Taquaritinga-SP. Em janeiro de 2006, foram colhidos aproximadamente $300 \mathrm{~g}$ (matéria fresca) de folhas jovens de uma única planta identificada de cada clone de umezeiro. As folhas foram armazenadas em sacos plásticos identificados e colocadas em caixa de isopor contendo gelo. Do mesmo modo, também foram colhidas folhas jovens de pessegueiro [Prunus persica (L.) Batsch] da cultivar-copa Aurora-1 e do porta-enxerto 'Okinawa' para serem utilizadas como "outgroup", sendo utilizada uma única planta de cada cultivar, ambas mantidas em condições de campo em área destinada à manutenção de plantas-matrizes, também localizada no Sítio São João.

b) Obtenção dos marcadores RAPD. Folhas jovens dos três clones foram utilizadas para extração do DNA conforme o protocolo de Shillito \& Saul (1988). A quantificação do DNA e sua qualidade foram avaliadas com o auxílio de um espectrofotômetro (BECKMAN-DU 640), medindo-se a absorbância de cada amostra em contraste com uma amostra de $\mathrm{H}_{2} \mathrm{O}$ destilada livre de DNA, nos comprimentos de onda de 260 e $280 \mathrm{~nm}$ (Sambrook et al., 1989).

A reação de amplificação do DNA genômico para a obtenção dos marcadores RAPD constituiu-se de $30 \mathrm{ng}$ de DNA genômico, tampão de PCR 1X (50 mM KCl, 200 mM Tris-HCl, pH $8,4)$ (Invitrogen, CA, USA), $2,5 \mathrm{mM} \mathrm{MgCl}_{2}$ (Invitrogen, CA, USA), $200 \mu \mathrm{M}$ dNTP(Invitrogen, CA, USA), 1,5 U Taq DNA polimerase (Invitrogen, CA, USA), 10 pmol de oligonucleotídeo iniciador ('primer') e água pura estéril q.s.p. para $20 \mu$ L. Foram utilizados 220 primers do Kit de primers Operon Technologies Inc..

A amplificação foi realizada em termociclador PTC 100 Programable Thermal Controler, MJ Research, Inc., e submetida a uma ciclagem de $92^{\circ} \mathrm{C}$ por $3 \mathrm{~min}, 47$ repetições de $\left(92^{\circ} \mathrm{C}\right.$ por 1 min, $36^{\circ} \mathrm{C}$ por 1 min e $45 \mathrm{~s} \mathrm{e} 72^{\circ} \mathrm{C}$ por $2 \mathrm{~min}$ ), $72^{\circ} \mathrm{C}$ por 7 min e um ciclo final a $5^{\circ} \mathrm{C}$.

Os produtos de amplificação foram submetidos à eletroforese em tampão TEB 1X (89 mM Tris; 89 mM Ácido Bórico; 2,5 mM EDTA, pH 8,3), utilizando géis de agarose a 1\%, contendo brometo de etídeo $(0,5 \mathrm{mg} / \mathrm{ml})$ durante $1 \mathrm{~h} 30 \mathrm{~min}$ a 90Volts. Como padrão de tamanho molecular, foi utilizado o marcador $1 \mathrm{~kb}$ DNA ladder plus (Invitrogen, CA, USA) e o marcador $100 \mathrm{pb}$ DNA ladder (Invitrogen, CA, USA). A visualização dos resultados foi realizada em equipamento de fotodocumentação Gel-Doc 1.000 (BioRad, CA, USA).

c) Análise dos marcadores obtidos. A análise dos marcadores foi realizada através da construção de uma matriz binária, na qual se analisaram a presença (1) e a ausência (0) de banda em cada material para os diferentes primers. A matriz binária 
gerada foi convertida em matriz de distância através do software PAUP (Phylogenetic Analysis Using Parcimony - versão 3.01) (Swofford, 2002). A matriz de distância obtida foi então analisada pelo software MEGA (versão 2.1) (Kumar et al., 2004), utilizandose do Método de Distância com algoritmo de agrupamento de Neighbour Joining (Saitou \& Nei, 1987) para a construção do filograma das relações filogenéticas desenvolvidas pelos clones e do cálculo dos índices de distância genética entre os materiais do estudo. A medida da distância genética interespecífica é uma medida da diversidade genética existente entre os indivíduos de um grupo em relação a outros grupos (Saitou \& Nei, 1987).

\section{RESULTADOS E DISCUSSÃO}

Após a determinação das melhores condições de amplificação, foram testados 220 primers, dos quais 42 amplificaram os genótipos de umezeiro e pessegueiro utilizados neste trabalho (Tabela 1). Dos 42 primers que amplificaram fragmentos de DNA para todos os materiais, 24 primers apresentaram polimorfismo para os clones de umezeiro, ou seja, $10,9 \%$ do total de primers testados. A Tabela 1 mostra que, nos 42 primers que amplificaram os genótipos de umezeiro, foram detectadas 432 bandas no total, sendo que 330 foram bandas monomórficas e 102 polimórficas $(23,6 \%)$ para o umezeiro. Observa-se também que, em 9 primers, foram detectadas 5 ou mais bandas polimórficas para o umezeiro. Já entre as duas cultivares de pessegueiro utilizadas como "outgroup", foram detectadas 346 bandas monomórficas e 86 bandas polimórficas.

Os primers OPC07 (Figura 1) e OPB12 (Figura 2) mostraram-se polimórficos em relação aos três clones, evidenciando a possibilidade de diferenciar os clones entre si e em relação ao outgroup. O primer OPC07 amplificou dois fragmentos exclusivos para Clone 05 , com aproximadamente 750 pb e $350 \mathrm{pb}$. Na cv. Rigitano, detectou-se a presença de um fragmento exclusivo de cerca de $1.490 \mathrm{pb}$. Esse primer permitiu a distinção dos três genótipos de umezeiro. Dessa forma, a identificação dos Clone 05, Clone 15 e da cv. Rigitano de umezeiro tornou-se facilitada e precisa, pois, com o uso de um único primer, foi possível identificar os genótipos, independentemente dos fatores ambientais existentes onde a planta se encontra. Já o primer OPB12 (Figura 2) permitiu a observação da presença de um fragmento polimórfico exclusivo para o Clone 15 com cerca de 420 pb. Esse primer, entretanto, não permitiu a discriminação do Clone 05 e da cv. Rigitano. Assim, a análise conjunta da amplificação obtida através dos primers OPC07 e OPB12 permitiu a discriminação através de bandas características para os três genótipos. Esse fato ocorreu para vários primers, de acordo com o exemplificado para os primers OPC07 e OPB12. Dessa forma, verificou-se que os marcadores moleculares RAPD foram eficientes na identificação dos clones.

Marcadores RAPD foram utilizados com sucesso no levantamento da diversidade genética existente entre 40 acessos do gênero Prunus, representando os subgêneros Prunophora (ao qual pertence P. mume), Amygdalus, Lithocerasus e Cerasus (Shimada et al., 2001). Os autores verificaram que 4 espécies pertencentes ao subgênero Lithocerasus apresentaram maior similaridade com membros dos subgêneros Prunophora e Amygdalus do que com Cerasus, sugerindo que os acessos estariam mais bem classificados se agrupados em apenas dois grupos: Prunophora-Amygdalus e Cerasus, uma vez que o subgenero Lithocerasus não é aceito por todos os taxonomistas.

Os mesmos marcadores mostraram-se eficientes no estudo da diversidade genética de 42 acessos de ameixeira (Prunus spp), sendo que foi possível identificar os acessos do grupo Europeu (P. domestica L., P. insititia L.) e do grupo Japonês (P. cerasifera Ehrh.), bem como os cruzamentos oriundos a partir desses dois grupos (Shimada et al., 1999), concordando com classificações já existentes.

Marcadores RAPD constituem-se a classe de marcadores moleculares mais utilizados atualmente (Sadder \& Ateyyeh, 2006). Isto se deve a suas características de rapidez e simplicidade na obtenção dos resultados, cobertura de todo o genoma do indivíduo em estudo, por sua facilidade de implementação e menor custo comparativo a outros marcadores. Por outro lado, são marcadores criticados por sua falta de repetibilidade quando são comparados resultados obtidos por diferentes laboratórios. Entretanto, o problema da repetibilidade pode ser evitado ao tomar-se uma série de cuidados em relação ao uso de DNA íntegro e puro, reagentes de qualidade e uso de um mesmo termociclador para todas as reações, além de repetir as reações pelo menos três vezes para a confirmação dos padrões de amplificação.

O conhecimento da distância genética entre porta-enxerto (genótipos de umezeiro) e a cultivar-copa (cv. Aurora-1 de pessegueiro) pode auxiliar nos estudos sobre compatibilidade de enxertia e ausência de sintomas de incompatibilidade, revelada nos estudos conduzidos na FCAV/UNESP, Câmpus de Jaboticabal-SP, com esses genótipos (Mayer, 2004; Mayer et al., 2006). Segundo Hartmann et al. (1997), a compatibilidade de enxertia só ocorre entre duas espécies botanicamente afins e próximas geneticamente.

Na Tabela 2, são apresentadas as distâncias genéticas existentes entre os cinco genótipos envolvidos no presente estudo. Verifica-se que a menor distância genética existente ocorre entre a cultivar Aurora-1 de pessegueiro com o porta-enxerto 'Okinawa' (0.171). Entre os três genótipos de umezeiro, observase que a menor distância genética ocorre entre o Clone 05 e o Clone 15 (0.305). A distância genética entre os genótipos também revela a maior proximidade genética dos três genótipos de umezeiro com a cv. Aurora-1 de pessegueiro (valores entre 0.595 e 0.614), comparativamente à encontrada entre os três genótipos de umezeiro com a cv. Okinawa (valores entre 0.662 e 0.700).

$\mathrm{O}$ número de bandas polimórficas entre os genótipos também é apresentado na Tabela 2. Observa-se que, entre os três genótipos de umezeiro, o número de bandas polimórficas foi maior (entre 64 e 70), comparativamente ao obtido entre as duas cultivares de pessegueiro (36). Esse resultado reflete a maior similaridade genética existente entre 'Aurora-1' e 'Okinawa', comparativamente à existente entre o Clone 05 , o Clone $15 \mathrm{e} \mathrm{a} \mathrm{cv.}$ Rigitano de umezeiro.

De acordo com o filograma apresentado na Figura 3, existe maior similaridade genética entre os Clones 05 e 15, com 
coeficiente de similaridade de aproximadamente 0.15. A cv. Rigitano, de acordo com os marcadores RAPD, apresentou similaridade de 0.17 , em relação aos Clones 05 e 15, revelando maior divergência genética em relação a estes.

O filograma também demonstra similaridade de aproximadamente 0.09 entre 'Okinawa' e 'Aurora-1'. O portaenxerto 'Okinawa', originário do programa de Melhoramento Genético da Universidade da Flórida, foi obtido de um lote de sementes enviado por Henriz Chikasne, de Okinawa, no Japão. Foi introduzido no Brasil em 1969, por meio de intercâmbio de material genético entre o IAC e a Universidade da Flórida (Ojima et al., 1999). A cultivar-copa Aurora-1 foi obtida, em segunda geração, do cruzamento entre o pessegueiro 'Tutu' (IAC 1353-1) e a nectarineira 'Colombina' (Fla 19-37 S), oriunda do Programa de Melhoramento Genético e Cultural do Instituto Agronômico de Campinas (Ojima et al., 1989). Por sua vez, a nectarineira 'Colombina' é originária de polinização livre de 'NJN21' ('Okinawa' x 'Panamint'), daí a similaridade genética existente entre 'Aurora1' e 'Okinawa' (Barbosa, 2007, comunicação pessoal).

Verifica-se que os marcadores RAPD se mostraram eficientes na discriminação dos três genótipos de umezeiro em estudo, bem como forneceram bandas específicas para cada clone com capacidade para serem convertidas em marcadores SCAR. Essa abordagem apresenta grande importância, pois ao identificarse molecularmente cultivares, é possível preservar o direito de propriedade bem como a proteção das cultivares, evitando a criação e proliferação de fraudes. Marcadores SCAR poderiam ser desenhados a partir dos fragmentos polimórficos para cada clone, permitindo a discriminação destes e facilitando a identificação no caso de dúvida em relação a materiais desconhecidos, se relacionados aos três clones em questão.

O uso das novas técnicas de biologia molecular na certificação de espécies frutíferas poderá acelerar e otimizar o processo de identificação de cultivares, pela caracterização molecular de cada genótipo em qualquer estádio de desenvolvimento, independentemente dos fatores ambientais que podem influenciar o fenótipo. Além disso, essas técnicas podem auxiliar em programas de melhoramento genético, selecionando genes de interesse, na construção de mapas genéticos, em estudos de similaridade e de distância genética entre cultivares e espécies, além de constituir eficientes métodos para o controle de qualidade e prevenção de fraudes (Mariniello et al., 2002; Wünsch \& Hormaza, 2002).
TABELA 1- Relação dos primers selecionados, com suas respectivas seqüências e número de bandas polimórficas (NBP) e número de bandas monomórficas (NBM) entre os clones de umezeiro (Clone 05, cv. Rigitano e Clone 15) e cultivares de pessegueiro (Okinawa e Aurora-1) estudados.

\begin{tabular}{|c|c|c|c|c|c|}
\hline \multirow[t]{2}{*}{ Primer } & \multirow[t]{2}{*}{ Sequência $5^{\prime}-3^{\prime}$} & \multicolumn{2}{|c|}{ umezeiro } & \multicolumn{2}{|c|}{ pessegueiro } \\
\hline & & NBP & NBM & NBP & NBM \\
\hline OPA03 & AGTCAGCCAC & 00 & 07 & 01 & 06 \\
\hline OPA04 & AATCGGGCTG & 00 & 10 & 05 & 05 \\
\hline OPA05 & AGGGGTCTTG & 02 & 09 & 02 & 09 \\
\hline OPA06 & GGTCCCTGAC & 03 & 02 & 00 & 05 \\
\hline OPB10 & CTGCTGGGAC & 01 & 06 & 00 & 07 \\
\hline OPB12 & CCTTGACGCA & 02 & 09 & 06 & 05 \\
\hline OPB17 & AGGGAACGAG & 00 & 14 & 05 & 09 \\
\hline OPC01 & TTCGAGCCAG & 03 & 03 & 00 & 06 \\
\hline OPCO2 & GTGAGGCGTC & 03 & 08 & 05 & 06 \\
\hline $\mathrm{OPCO3}$ & GGGGGTCTTT & 05 & 04 & 04 & 05 \\
\hline OPC07 & GTCCCGACGA & 12 & 05 & 03 & 14 \\
\hline OPC08 & TGGACCGGTG & 01 & 06 & 01 & 06 \\
\hline OPCO9 & CTCACCGTCC & 04 & 09 & 03 & 10 \\
\hline OPC10 & TGTCTGGGTG & 00 & 11 & 04 & 07 \\
\hline OPC11 & AAAGCTGCGG & 00 & 08 & 02 & 06 \\
\hline $\mathrm{OPCl} 2$ & TGTCATCCCC & 04 & 04 & 02 & 06 \\
\hline OPCl4 & TGCGTGCTTG & 03 & 08 & 00 & 11 \\
\hline OPC15 & $\begin{array}{l}\text { GACGGATCAG } \\
\end{array}$ & 00 & 04 & 02 & 02 \\
\hline OPC17 & TTCCCCCCAG & 05 & 08 & 04 & 09 \\
\hline OPC18 & TGAGTGGGTG & 00 & 14 & 01 & 13 \\
\hline OPC19 & GTTGCCAGCC & 00 & 09 & 01 & 08 \\
\hline OPC20 & ACTTCGCCAC & 03 & 12 & 02 & 13 \\
\hline OPD03 & $\begin{array}{l}\text { GTCGCCGTCA } \\
\end{array}$ & 00 & 05 & 01 & 04 \\
\hline 0PD07 & TTGGCACGGG & 00 & 05 & 00 & 05 \\
\hline OPD08 & $\begin{array}{l}\text { GTGTGCCCCA } \\
\end{array}$ & 00 & 12 & 06 & 06 \\
\hline OPD11 & AGCGCCATTG & 00 & 09 & 03 & 06 \\
\hline OPD13 & GGGGTGACGA & 01 & 12 & 00 & 13 \\
\hline OPD20 & ACCCGGTCAC & 00 & 09 & 04 & 05 \\
\hline OPF09 & CCAAGCTTCC & 00 & 09 & 00 & 09 \\
\hline OPH05 & AGTCGTCCCC & 07 & 02 & 03 & 06 \\
\hline OPHOP & GAAACACCCC & 07 & 06 & 01 & 12 \\
\hline OPHI2 & ACGCGCATGT & 06 & 12 & 03 & 15 \\
\hline OPHI4 & ACCAGGTTGG & 00 & 06 & 01 & 05 \\
\hline OPHI6 & TCTCAGCTGG & 01 & 11 & 01 & 11 \\
\hline OPH17 & GAATCGGCCA & 08 & 05 & 02 & 11 \\
\hline OPI02 & GGAGGAGAGG & 00 & 07 & 01 & 06 \\
\hline OPI06 & AAGGCGGCAG & 00 & 08 & 01 & 07 \\
\hline OPI07 & CAGCGACAAG & 01 & 10 & 01 & 10 \\
\hline OPI13 & CTGGGGCTGA & 03 & 06 & 00 & 09 \\
\hline OPII4 & TGACGGCGGT & 00 & 10 & 02 & 08 \\
\hline OPI17 & GGTGGTGATG & 06 & 08 & 03 & 11 \\
\hline OPII8 & TGCCCAGCCT & 11 & 08 & 00 & 19 \\
\hline $\begin{array}{c}\text { Total } \\
\text { (NBPe NBM) }\end{array}$ & - & 102 & 330 & 86 & 346 \\
\hline $\begin{array}{l}\text { Total de bandas } \\
\text { por espécie }\end{array}$ & - & & & & \\
\hline
\end{tabular}

TABELA 2- Distância genética e número de bandas polimórficas (em itálico) entre o Clone 05, cv. Rigitano e Clone 15 de umezeiro (Prunus mume Sieb. et Zucc.) e cultivares Okinawa e Aurora-1 de pessegueiro obtidas com o uso de marcadores RAPD.

\begin{tabular}{cccccc}
\hline & Clone 05 & 'Rigitano' & Clone 15 & 'Okinawa' & 'Aurora-1' \\
\hline Clone 05 & - & 0.333 & 0.305 & 0.700 & 0.605 \\
'Rigitano' & 70 & - & 0.324 & 0.681 & 0.614 \\
Clone 15 & 64 & 68 & - & 0.662 & 0.595 \\
'Okinawa' & 147 & 143 & 139 & - & 0.171 \\
'Aurora-1' & 127 & 129 & 125 & 36 & - \\
\hline
\end{tabular}




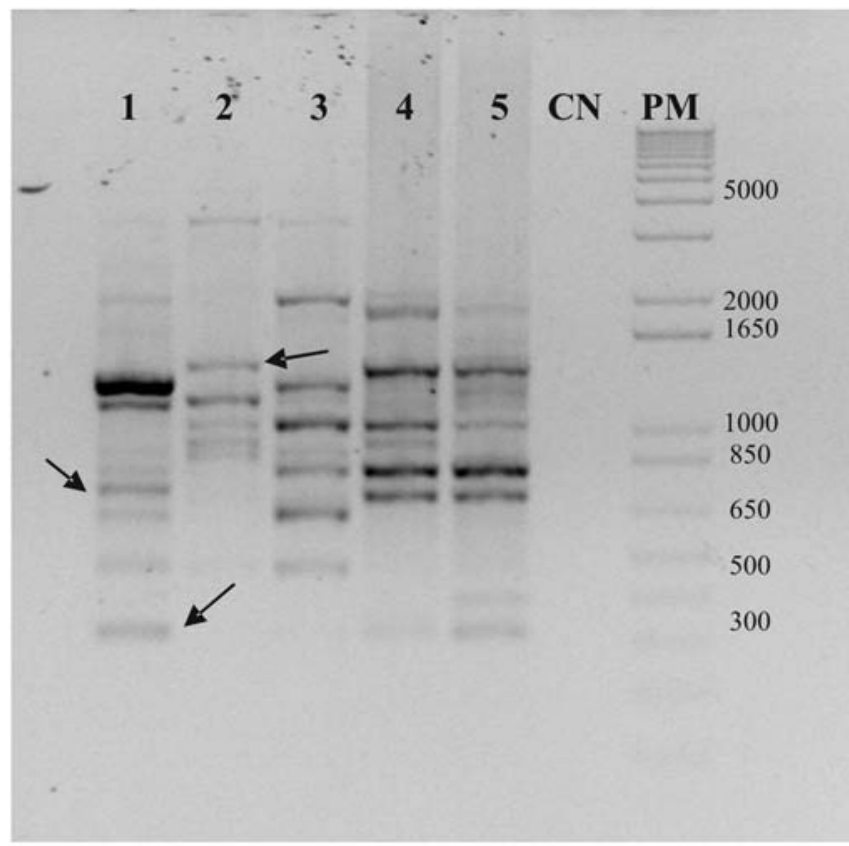

FIGURA 1- Produto da amplificação por RAPD utilizando-se do primer OPB12 com presença de fragmentos exclusivos indicados por seta. $\mathrm{PM}=$ padrão de tamanho molecular $1 \mathrm{~Kb}$ DNA Plus Ladder (Invitrogen). $\mathrm{CN}=$ controle negativo da PCR, $1=$ Clone 05; 2 = cv. Rigitano; 3 = Clone 15; 4 = 'Okinawa'; 5 = 'Aurora-1'.

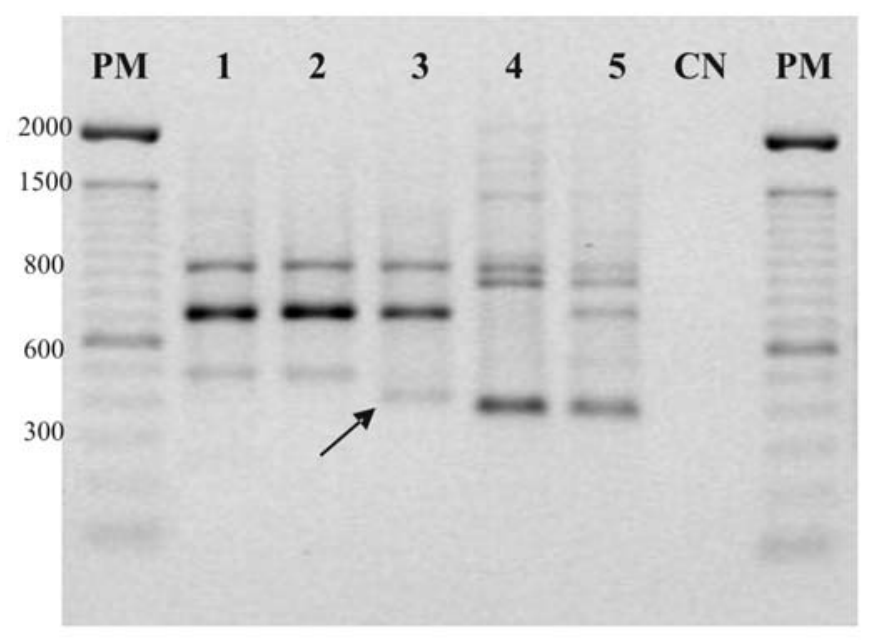

FIGURA 2- Produto da amplificação por RAPD utilizando-se do primer OPC07 com presença de fragmentos exclusivos indicados por seta. PM = padrão de tamanho molecular $1 \mathrm{~Kb}$ DNA Plus Ladder (Invitrogen). $\mathrm{CN}=$ controle negativo da PCR, $1=$ Clone 05; $2=\mathrm{cv}$. Rigitano; $3=$ Clone 15; $4=\mathrm{cv}$. Okinawa; $5=\mathrm{cv}$. Aurora- 1 .

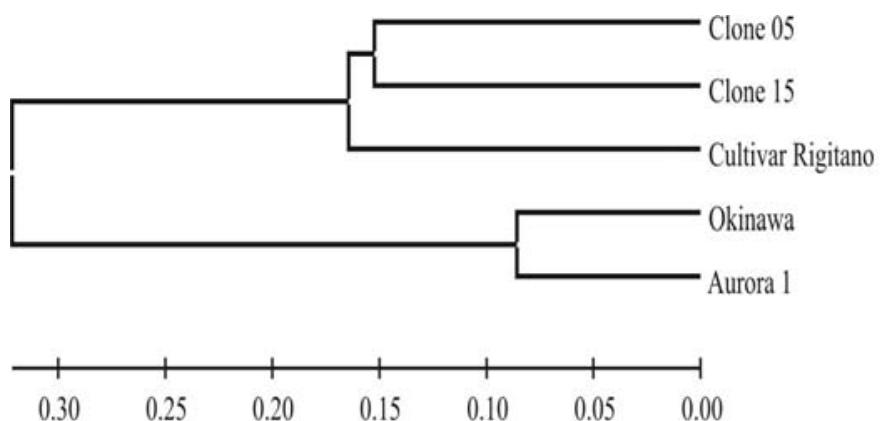

FIGURA 3- Relações filogenéticas estabelecidas entre os genótipos de umezeiro verificadas por marcadores moleculares RAPD. Pessegueiros 'Aurora-1' e 'Okinawa' foram utilizados como "outgroup".

\section{CONCLUSÕES}

1-Os marcadores RAPD permitiram a distinção do Clone 05, do Clone 15 e da cv. Rigitano de umezeiro, selecionados na FCAV/UNESP, como porta-enxertos para pessegueiro.

2-Os primers OPC07 e OPB12 revelaram bandas polimórficas que permitiram a distinção do Clone 05 , do Clone 15 e da cv. Rigitano entre si.

3-Dentre os três genótipos de umezeiro estudados, constatou-se que a similaridade genética é maior entre o Clone 05 e o Clone 15.

\section{AGRADECIMENTOS}

À Fapesp, pelo apoio financeiro (Processos $\mathrm{n}^{\mathrm{os}} 05 /$ 50157-7 e 06/50427-7).

\section{REFERÊNCIAS}

CASAS, A.M.; IGARTUA, E.; BALAGUER, G.; MORENO, M.A. Genetic diversity of Prunus rootstocks analyzed by RAPD markers. Euphytica, Wageningen, n.110, p.139-149, 1999.

HARTMANN, H.T.; KESTER, D.E.; DAVIES JR., F.T.; GENEVE, R.L. Plant propagation: principles and practices. $6^{\text {th }}$ ed. New Jersey: Prentice Hall, 1997. 770p.

KUMAR, S.; TAMURA, K.; AND NEI, M. MEGA3: Integrated software for Molecular Evolutionary Genetics Analysis and sequence alignment. Briefings in Bioinformatics, London, n.5, p.150-163, 2004.

MARINIELLO, L.; SOMMELLA, M.G.; SORRENTINO, A.; FORLANI, M.; PORTA, R. Identification of Prunus armeniaca cultivars by RAPD and SCAR markers. Biotechnology Letters, Surrey, n.24, p.749-755, 2002. 
MAYER, N.A.; PEREIRA, F.M.; NACHTIGAL, J.C. Propagação do umezeiro (Prunus mume Sieb \& Zucc.) por estaquia herbácea. Revista Brasileira de Fruticultura, Jaboticabal, v.23, n.3, p.673676,2001

MAYER, N.A.; PEREIRA, F.M.; SANTOS, J.M. dos. Reação de clones de umezeiro (Prunus mume Sieb. et Zucc.) e cultivares de pessegueiro a Meloidogyne javanica (Treub, 1885) Chitwood, 1949. Revista Brasileira de Fruticultura, Jaboticabal, v.25, n.1, p.181-183, 2003.

MAYER, N.A. Crescimento de clones de umezeiro (Prunus mume Sieb. et Zucc.) propagados por estacas herbáceas, enxertia com o pessegueiro [Prunus persica (L.) Batsch], reação a três espécies de fitonematóides e desenvolvimento inicial no campo. 2004. 114 f. Tese (Doutorado em Agronomia) - Faculdade de Ciências Agrárias e Veterinárias, Universidade Estadual Paulista, Jaboticabal, 2004.

MAYER, N.A.; PEREIRA, F.M.; SANTOS, J.M. dos. Resistência de clones de umezeiro e cultivares de pessegueiro a Meloidogyne incognita (Nemata: Heteroderidae). Revista Brasileira de Fruticultura, Jaboticabal, v.27, n.2, p.335-337, 2005.

MAYER, N.A.; PEREIRA, F.M. Vigor de clones de umezeiro e pessegueiro 'Okinawa' propagados por estacas herbáceas. Pesquisa Agropecuária Brasileira, Brasília, v.41, n.5, p.883-887, 2006.

MAYER, N.A.; PEREIRA, F.M.; KOBA, V.Y. Desenvolvimento inicial no campo de pessegueiros Aurora-1 enxertados em clones de umezeiro e Okinawa propagados por estacas herbáceas. Revista Brasileira de Fruticultura, Jaboticabal, v.28, n.2, p.231$235,2006$.

NACHTIGAL, J.C.; PEREIRA, F.M.; CAMPO DALLORTO, F.A.; OJIMA, M.; MARTINS, F.P. Propagação vegetativa do umezeiro (Prunus mume) por meio de estacas herbáceas. Revista Brasileira de Fruticultura, Jaboticabal, v.21, n.2, p.226-228, 1999.

OJIMA, M.; CAMPO DALLORTO, F.A.; BARBOSA, W.; MARTINS, F.P.; SANTOS, R.R.; RIGITANO, O. Aurora-1 e Aurora-2: novas cultivares de pêssego doce de polpa amarela. In: CONGRESSO BRASILEIRO DE FRUTICULTURA, 10., 1989, Fortaleza. Anais... Fortaleza: SBF, 1989. p.422-425.
OJIMA, M.; CAMPO DALLORTO, F.A.; BARBOSA, W.; MARTINS, F.P.; SANTOS, R.R. dos. Propagação do pessegueiro: pesquisas no Instituto Agronômico. Campinas: Instituto Agronômico, 1999. 42p. (Documentos, 64).

PEREIRA, F.M.; MAYER, N.A.; CAMPO DALLORTO, F.A. Rigitano: nova cultivar de umezeiro para porta-enxerto de pessegueiro. Revista Brasileira de Fruticultura, Jaboticabal, v.29, n.1, p.172-175, 2007.

SADDER, M. T.; ATEYYEH, A. F. Molecular assessment of polymorphism among local Jordanian access of commom fig (Ficus carica L.). Acta Horticulturae, The Hague, v.107, p.345351, 2006.

SAITOU, N.; NEI, M. The neighbor-joining method: A new method for reconstructing phylogenetic trees. Molecular Biology and Evolution, Chicago, v.4, p.406-425, 1987.

SAMBROOK, J.; MANIATIS, T.; FRITSH, E. F. Molecular cloning: a laboratory manual. $2^{\text {nd }}$ ed. New York: Cold Sprig Harbor Laboratory, 1989.

SHILLITO, R.D.; SAUL, M.W. Protoplast isolation and transformation. In: GRIERSON, D., COVEY, S.N. Plant nolecular biology: a practical approach. Oxford: IRL Press, 1988. p.161-186.

SHIMADA, T.; HAYAMA, H.; HAJI, T.; YAMAGUCHI, M.; YOSHIDA, M. Genetic diversity of plums characterized by random amplified polymorphic DNA (RAPD) analysis. Euphytica, Wageningen, n.109, p.143-147, 1999.

SHIMADA, T.; HAYAMA, H.; NISHIMURA, K.; YAMAGUCHI, M.; YOSHIDA, M. The genetic diversities of 4 species of subg. Lithocerasus (Prunus, Rosaceae) revealed by RAPD analysis. Euphytica, Wageningen, n.117, p.85-90, 2001.

SWOFFORD, D. L. PAUP: phylogenetic analysis using parsimony (and other methods) 4.0 beta. Sunderland: Sinauer, 2002 .

WÜNSCH, A.; HORMAZA, J.I. Cultivar identification and genetic fingerprinting of temperate fruit tree species using DNA markers. Euphytica, Wageningen, n.125, p.59-67, 2002. 